\title{
Physical-chemical characterization of a galvanic sludge and its inertization by vitrification using container glass
}

\author{
F. Andreola, L. Barbieri, M. Cannio, I. Lancellotti, C. Siligardi \\ \& E. Soragni \\ Dipartimento di Ingegneria dei Materiali e dell'Ambiente, \\ University of Modena and Reggio Emilia, Modena, Italy
}

\begin{abstract}
Several industrial processes produce large amounts of heavy metals-rich wastes, which could be considered as "trash-can raw materials". The incorporation in ceramic systems can be regarded as a key process to permanently incorporate hazardous heavy metals in stable matrixes. In particular the aim of this work is to prepare and evaluate environmental risk assessment of coloured glass and glass-ceramic with the addition of chromium(III) galvanic sludge having a high content of $\mathrm{Cr}_{2} \mathrm{O}_{3}(15.91 \mathrm{wt} \%)$. Trivalent chromium compounds generally have low toxicity while hexavalent chromium is recognized by the International Agency for Research on Cancer and by the US Toxicology Program as a pulmonary carcinogen. The sludge has been characterized by ICP -AES chemical analysis, powder XRD diffraction, DTA, SEM, leaching test after different thermal treatments ranging from $400^{\circ} \mathrm{C}$ to $1200^{\circ} \mathrm{C}$. Batch compositions were prepared by mixing this sludge with glass containers. The glass container composition is rich in $\mathrm{SiO}_{2}(69.89 \mathrm{wt} \%), \mathrm{Na}_{2} \mathrm{O}(12.32 \mathrm{wt} \%)$ and $\mathrm{CaO}$ (11.03 wt\%), while the sludge has a high amount of $\mathrm{CaO}(42.90 \mathrm{wt} \%)$ and $\mathrm{Cr}_{2} \mathrm{O}_{3}$ $(15.91 \mathrm{wt} \%)$. The vitrification was carried out at $1450^{\circ} \mathrm{C}$ in an electrical melting furnace for $2 \mathrm{~h}$ followed by quenching in water or on graphite mould. Chromium incorporation mechanisms, vitrification processability, effect of initial $\mathrm{Cr}$ oxidation state, and product performance were investigated. In particular toxic characterization by leaching procedure and chemical durability studies of the glasses and glass-ceramics were used to evaluate the leaching of heavy metals (in particular of $\mathrm{Cr}$ ). The results indicate that all the glasses obtained were inert and the heavy metals were immobilized.

Keywords: chromium electroplating sludge, thermal behaviour; vitrification, chemical glass durability.
\end{abstract}




\section{Introduction}

Chromium has been used in industry for various applications over a century, including steel production, plating, anodising of aluminium, leather tanning, wood preservation, water-cooling, etc. The use of chromium (VI) containing solutions $\left(\mathrm{CrO}_{3} 250 \mathrm{~g} / \mathrm{l}\right.$ and $\left.\mathrm{H}_{2} \mathrm{SO}_{4} 2,5 \mathrm{~g} / \mathrm{l}\right)$ as deposition metal is the unique technique employed in the plating industry [1], despite of its high toxicity [2]. After electroplating is completed, the plated parts are rinsed with water. Eventually this rinse water becomes highly contaminated with plating solution and must be replaced. This fact presents a serious environmental problem since the water is highly concentrated in chromate ions. The hazardousness of this galvanic waste is not only due to $\mathrm{Cr}(\mathrm{VI})$ presence but also to the high concentration of heavy metals, as $\mathrm{Ni}$, $\mathrm{Ti}$, etc. This chromium rich solution needs a chemical treatment based on a two-stage process: the first stage reduces hexavalent chromium $\mathrm{Cr}(\mathrm{VI})$ to a harmless $\mathrm{Cr}_{2}\left(\mathrm{SO}_{4}\right)_{3}$ by using chemical agents as sodium bisulfate $\left(\mathrm{NaHSO}_{3}\right)$, sodium or calcium meta-bisulfite $\left(\mathrm{Na}_{2} \mathrm{~S}_{2} \mathrm{O}_{5}\right)$. In the second stage trivalent chromium and other metals are precipitated by the addition of calcium or sodium hydroxide in their hydroxide form, which can be easily separated and disposed in landfills. Nowadays the cost of landfill disposal and the decrease in the number of disposal sites have led to considerate stabilization of waste into a glassy matrix or ceramic materials an accepted treatment process $[3,4]$. In the last 30 years it has been reported many examples about recycling of industrial waste in cement, glass, and metallurgy industry [5], but few works can be found in literature regarding recycling of galvanic chromium sludge [6] into glassy matrixes or ceramics compounds [7].

The aim of this work is to characterize the chromium galvanic sludge and to study the vitrification process as an efficient method to immobilize the hazardous components of this galvanic waste. In particular it is investigated the stabilization process evaluating the chemical resistance of the obtained glasses and glass-ceramics compounds.

\section{Experimental}

The electroplating sludge employed in this investigation has been collected from a local plant, while the glass is from container waste. These wastes have been characterized by ICP -AES technique (Varian, Liberty 200). Galvanic sludge previously milled for $40 \mathrm{~min}$ in a porcelain jar was added in the percentages of $0.5,1.5,3,6 \mathrm{wt} \%$ corresponding to $\mathrm{Cr}_{2} \mathrm{O}_{3}$ content of $0.12,0.25,0.5$ and $1 \mathrm{wt} \%$ to the container glass composition and the dry mixtures were ground in a ball-mill for $20 \mathrm{~min}$. The mixture was fired in mullite crucibles at $1450^{\circ} \mathrm{C}$ for $1 \mathrm{~h}$ in electrical melting furnace. The melts have been quenched in water to obtained the frits or poured into a graphite mould and quenched in air to obtain a bar shape glass. The glass shape were heated at $750^{\circ} \mathrm{C}$ with $1 \mathrm{~h}$ of soaking time to eliminate the internal stresses due to the fast cooling rate in air. Frits can facilitate and reduce the time required to ground in the preparation of glass ceramics. The container glass and frits in the above reported composition have 
been humidified with $6 \mathrm{wt} \%$ of water and pressed in order to obtain cylindrical samples. Subsequently these pellets were fired at different temperatures from 600 to $1000^{\circ} \mathrm{C}$ obtaining glass ceramics.

The mineralogical analysis of the galvanic sludge and glass-ceramics has been carried out by an X-ray $(\mathrm{CuK} \alpha)$ powder diffractometer, XRD (Philips PW 3710 , Holland). The XRD patterns were collected in the $5-60^{\circ}(2 \theta)$ range at room temperature. The thermal behaviour of chromium galvanic waste has been characterized by means of differential thermal analysis (DTA and TG) (Netzsch DSC 404). Scanning electron microscopy (SEM) (PHILIPS XL 40) has been performed on representative samples of sludge and glass-ceramics to observe phase distribution and microstructural features. Furthermore the assessment of the chemical durability in water, acid $(\mathrm{HCl} 6 \mathrm{M}$ boiling, $3 \mathrm{~h})$ and alkaline $\left(\mathrm{NaCO}_{3}\right.$ $0.5 \mathrm{M}$ and $\mathrm{NaOH} 1 \mathrm{M}$. boiling, $1 \mathrm{~h}$ ) conditions was carried out on representative specimens of the manufactured glasses following ISO/R 719, ISO/R 695 and DIN 12116 standards [8].

\section{Results and discussion}

\subsection{Thermal behaviour of chromium electroplating sludge}

The chemical analysis of galvanic waste indicates the following composition in wt\%: $0.81 \mathrm{SiO}_{2}, 0.8 \mathrm{Al}_{2} \mathrm{O}_{3}, 42.50 \mathrm{CaO}, 1 \mathrm{MgO}, 6.1 \mathrm{Na}_{2} \mathrm{O}, 0.5 \mathrm{~K}_{2} \mathrm{O}, 1.3 \mathrm{Fe}_{2} \mathrm{O}_{3}$, $0.01 \mathrm{TiO}_{2}, 0.2 \mathrm{NiO}, 0.5 \mathrm{CuO}, 0.2 \mathrm{MnO}, 15.91 \mathrm{Cr}_{2} \mathrm{O}_{3}, 0.02 \mathrm{CoO}, 0.02 \mathrm{CdO}$ and the L.OI is $30 \%$ Figure 1 illustrates the TG and DTA curves of the galvanic sludge during the heating process.

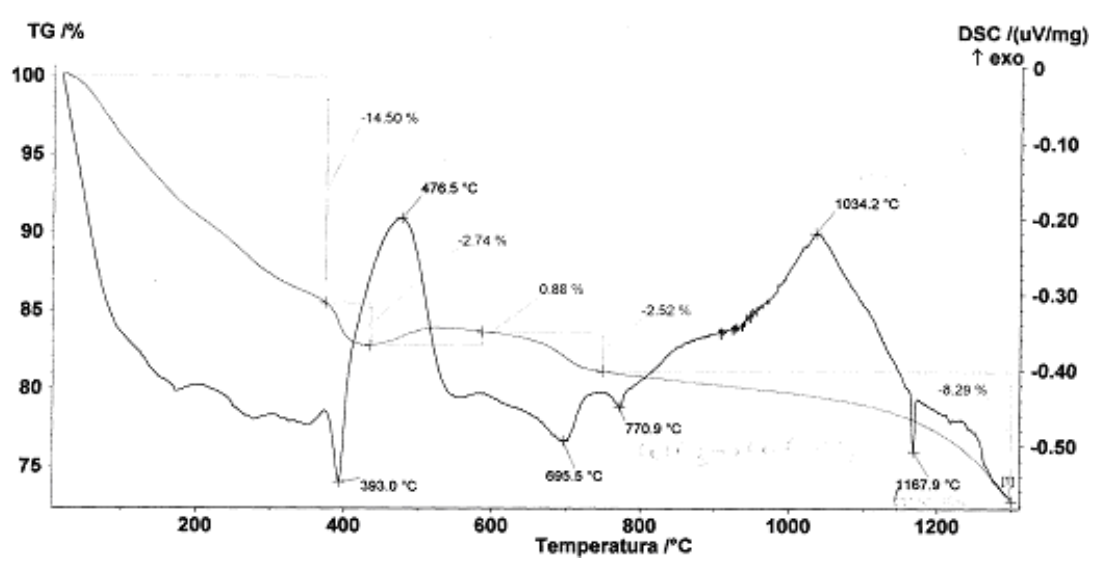

Figure 1: $\quad$ DTA and TG curves of as-received galvanic sludge.

The DTA curve shows exothermic peaks at 476.5 and $1034.2^{\circ} \mathrm{C}$, while endothermic peaks appeared at $393,695.5,770.9$ and $1167.9^{\circ} \mathrm{C}$. The total weight loss is $28 \%$. This result is in close agreement with that obtained from 
calculations based on chemical analysis and calcination at $1200^{\circ} \mathrm{C}$ (about $30 \%$ ) It is presumed that the weight loss is related to $\mathrm{CO}_{2}, \mathrm{H}_{2} \mathrm{O}$. The exothermic peak at $393^{\circ} \mathrm{C}$ is probably related to the release of cristallization water; the peak at $770.9^{\circ} \mathrm{C}$ corresponds to the $\mathrm{CaCO}_{3}$ decomposition and $1034.2^{\circ} \mathrm{C}$ could be due to a crystallization. The endothermic peak at $475^{\circ} \mathrm{C}$ represents the organic compound combustion and the one at $1167.9^{\circ} \mathrm{C}$ could be a melting reaction. $\mathrm{X}$ ray diffraction was performed in the as received waste and in samples previously submitted to different isothermal treatments from 400 to $1200^{\circ} \mathrm{C}$ with $1 \mathrm{~h}$ of soaking time. Fig. 2 resumes the XRD data showing $\mathrm{CaSO}_{4}, \mathrm{Na}_{2} \mathrm{SO}_{4}, \mathrm{CaCrO}_{4}$ and $\mathrm{CaCO}_{3}$ as main constituents, labelled a, b, c, and d respectively.

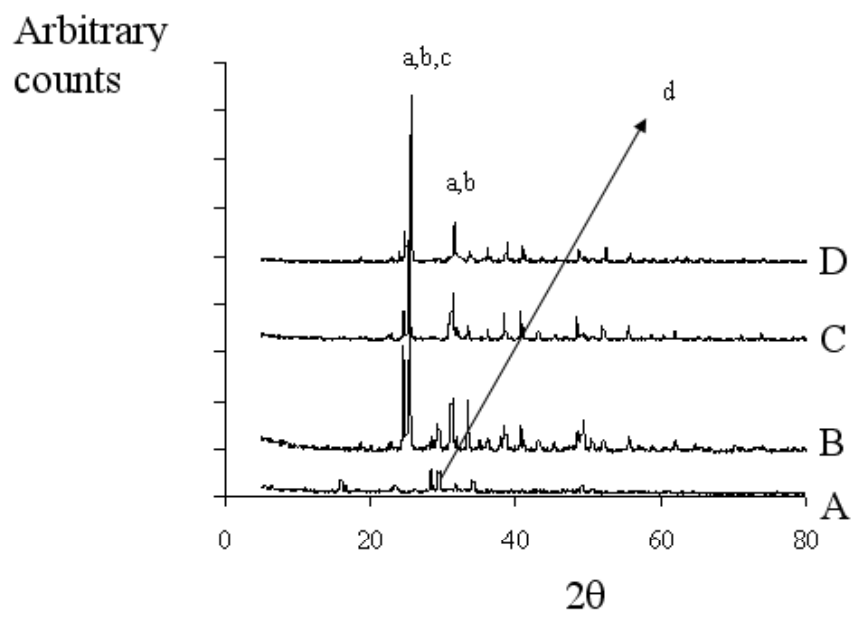

Figure 2: $\quad \mathrm{XRD}$ spectra of galvanic sludge dried at $105^{\circ} \mathrm{C}(\mathrm{A})$ and thermally treated at $500^{\circ} \mathrm{C}(\mathrm{B}), 800^{\circ} \mathrm{C}(\mathrm{C})$ and $1200^{\circ} \mathrm{C}(\mathrm{D})$ respectively

It is important to observe, in agreement with the DTA results, that the $\mathrm{CaCO}_{3}$ peaks disappear at $800^{\circ} \mathrm{C}$. The elementary analyses performed on the dried samples and on those obtained at 700 and $800^{\circ} \mathrm{C}$ show a decrease in $\mathrm{C}$, confirming the $\mathrm{CaCO}_{3}$ decomposition, as Table 1 reports.

Table 1: Elementary analysis of galvanic sludge dried at $105^{\circ} \mathrm{C}$ and thermally treated at different temperatures from $700^{\circ} \mathrm{C}$ up to $1200^{\circ} \mathrm{C}$.

\begin{tabular}{|l|l|l|l|l|}
\hline Sample & $\mathrm{N} \%$ & $\mathrm{C} \%$ & $\mathrm{H} \%$ & $\mathrm{~S} \%$ \\
\hline $105^{\circ} \mathrm{C}$ & 0.00 & 1.76 & 1.91 & 10.99 \\
\hline $700^{\circ} \mathrm{C}$ & 0.00 & 0.64 & 0.00 & 9.59 \\
\hline $800^{\circ} \mathrm{C}$ & 0.00 & 0.00 & 0.00 & 9.50 \\
\hline $1000^{\circ} \mathrm{C}$ & 0.00 & 0.00 & 0.00 & 6.53 \\
\hline $1200^{\circ} \mathrm{C}$ & 0.00 & 0.00 & 0.00 & 6.39 \\
\hline
\end{tabular}




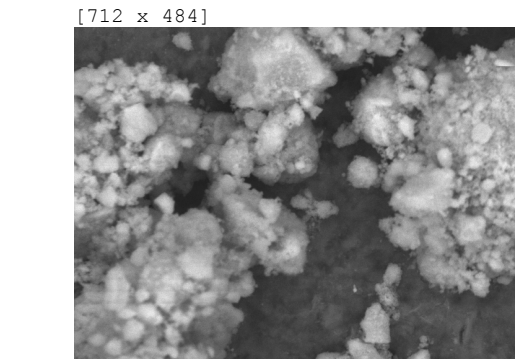

$5 \mu \mathrm{m}$.

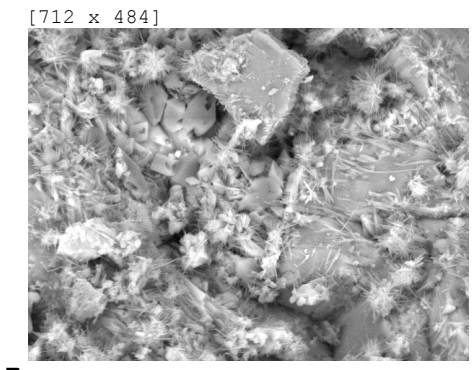

$5 \mu \mathrm{m}$

Figure 3: $\quad$ SEM micrographs of dried galvanic sludge and thermally treated at $1100^{\circ} \mathrm{C}$.

\subsubsection{Glasses and glass ceramic characterization}

Table 2 reports the chemical composition from theoretical calculations and the ICP chemical analysis of the V1 and V2 glasses. It is evident from these results that a very low crucible refractory contamination occurs. In fact, it can be observed an increase in the amount of $\mathrm{Al}_{2} \mathrm{O}_{3}$. It is important to remark that no significant variation of the $\mathrm{Cr}_{2} \mathrm{O}_{3}$ percentage is recorded. This fact indicates that vitrification could be considered a good alternative to stabilize wastes with a high content of heavy metals.

Table 2: Chemical composition from theoretical calculations of V1, V2, V3 and V4 and the ICP chemical analysis of the V1 and V2 glasses.

\begin{tabular}{l|llllll}
\hline Oxide & $\begin{array}{l}\text { V1 } \\
\text { Theoret. } \\
\text { wt } \%\end{array}$ & $\begin{array}{l}\text { V2 } \\
\text { Theoret. } \\
\text { wt } \%\end{array}$ & $\begin{array}{l}\text { V3 } \\
\text { Theoret. } \\
\text { wt } \%\end{array}$ & $\begin{array}{l}\text { V4 } \\
\text { Theoret. } \\
\text { wt } \%\end{array}$ & $\begin{array}{l}\text { ICP } \\
\text { V1 } \\
\text { wt } \%\end{array}$ & $\begin{array}{l}\text { ICP } \\
\text { V2 } \\
\text { wt } \%\end{array}$ \\
\hline $\mathrm{SiO}_{2}$ & 69.57 & 69.21 & 68.52 & 67.18 & 68 & 68.5 \\
$\mathrm{Al}_{2} \mathrm{O}_{3}$ & 2.64 & 2.62 & 2.6 & 2.55 & 6.2 & 7.1 \\
$\mathrm{CaO}$ & 11.28 & 11.56 & 12.1 & 13.50 & 10.57 & 11.50 \\
$\mathrm{MgO}$ & 2.24 & 2.24 & 2.23 & 2.20 & 1.92 & 2.22 \\
$\mathrm{Na}_{2} \mathrm{O}$ & 12.27 & 12.24 & 12.2 & 12.10 & 11.61 & 12.30 \\
$\mathrm{~K}_{2} \mathrm{O}$ & 1.48 & 1.47 & 1.46 & 1.45 & 1.51 & 1.42 \\
$\mathrm{Fe}_{2} \mathrm{O}_{3}$ & 0.12 & 0.12 & 0.13 & 0.15 & 0.19 & 0.13 \\
$\mathrm{BaO}$ & 0.13 & 0.13 & 0.13 & 0.13 & 0.12 & 0.11 \\
$\mathrm{ZrO}$ & 0.13 & 0.14 & 0.14 & 0.13 & 0.13 & 0.13 \\
$\mathrm{Cr}_{2} \mathbf{O}_{\mathbf{3}}$ & $\mathbf{0 . 1 2}$ & $\mathbf{0 . 2 5}$ & $\mathbf{0 . 4 9}$ & $\mathbf{0 . 9 6}$ & $\mathbf{0 . 1 1}$ & $\mathbf{0 . 2 2}$ \\
\hline
\end{tabular}

The water chemical durability of the obtained glasses remains constant with respect to container glass up to $3 \%$ in waste showing a medium resistance [8].

These results are in agreement with the increase of $\mathrm{pH}$ and conductivity observed with the increasing waste percentage. The damage of the glass network lead to a release of $\mathrm{OH}^{-}$and therefore to an increase in $\mathrm{pH}$, while an increase of 
the mobile ions $\mathrm{Na}^{+}$and $\mathrm{K}^{+}$, which are easily leached, causes an increase in conductivity. The examined glasses are slightly attacked in basic and acid medium. The weight loss of the glass containing $6 \mathrm{wt} \%$ of galvanic waste, expressed as weight loss per surface unit, is equal to $174 \mathrm{mg} / 100 \mathrm{~cm}^{2}$ and $2.69 \mathrm{mg} / 100 \mathrm{~cm}^{2}$ in alkali and acid respectively [8].

In order to verify the possibility to obtain a semi-crystalline technologically interesting such as glass-ceramics different thermal treatments have been performed on the glassy samples. XRD analysis shows the presence of crystalline phases dispersed in the glassy matrix, in particular wollastonite is the main crystalline phase (Fig.4).

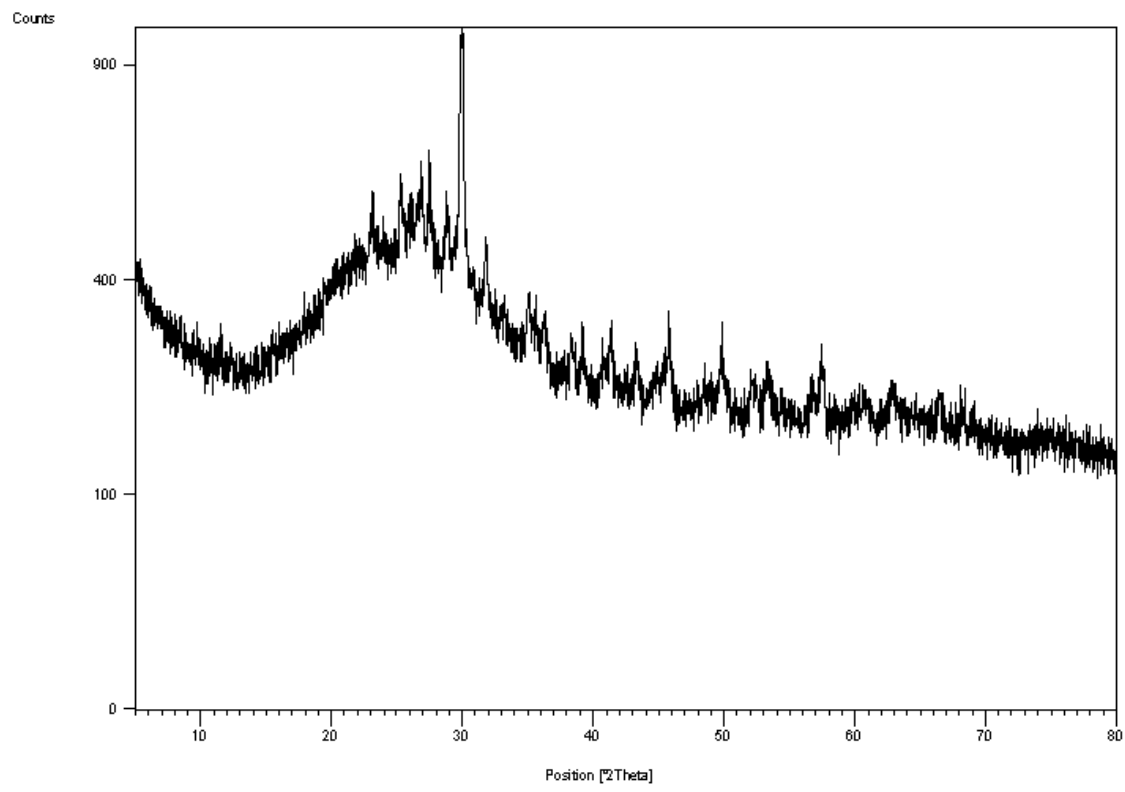

Figure 4: $\quad \mathrm{XRD}$ spectrum of a sample fired at $900^{\circ} \mathrm{C}$ showing wollastonite as main crystalline phase.

Figure 5 shows a SEM micrograph of a sample of these glass-ceramics compounds showing a microstructure where needle grains of a crystalline phase, that could be wollastonite, are embedded in an amorphous glassy matrix. These needle like grains are presented in the glass-ceramic microstructure from $750^{\circ} \mathrm{C}$ (Fig.5). The porosity of these glass-ceramic results low, which could be an indication of good mechanical properties.

\section{Conclusions}

The results of this investigation highlight the possibility of incorporating galvanic waste as economical raw material in glassy products. Adequate thermal 
treatments could lead to the production of glass-ceramic products. Therefore vitrification and devitrification could represent adequate techniques for inertization of industrial sludge with heavy metals content and alternatives to the disposal in landfills. In future more studies will be performed both on glasses and glass ceramics to evaluate the influence of an increase in the amount of galvanic sludge on the chemical and mechanical properties of the products and to better analyse the sintering process.

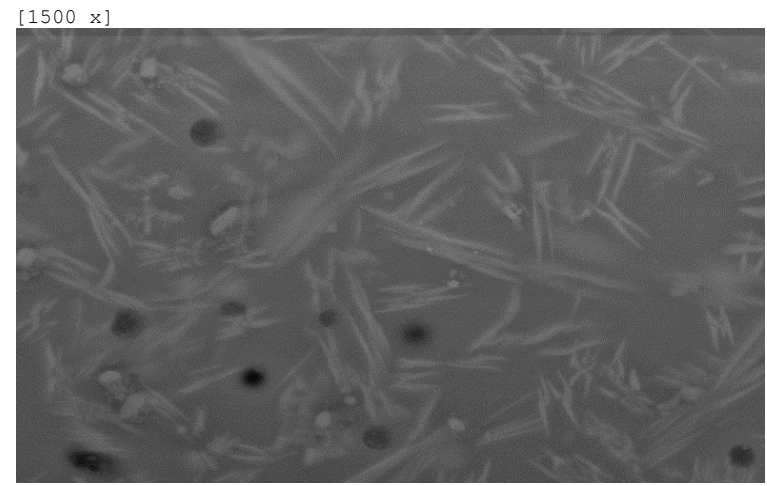

Figure 5: $\quad$ SEM micrograph of a sample fired at $750^{\circ} \mathrm{C}$ showing needle-like grains of wollastonite crystalline phase.

\section{Acknowledgement}

We are grateful to MIUR for financial support.

\section{References}

[1] Fink C. G., U.S. Pat. 1581188, 1926.

[2] Katz S.A., Salem H., The Biological and Environmental Chemistry of Chromium, Verlag Chemie, Weinheim, 1994.

[3] Andreola F., Barbieri L., Corradi A., Lancellotti I., Falcone R., Hreglish S., Glass-ceramics obtained by the recycling of end life cathode ray tubes glasses, Waste Management 25, 2005, pp.183-189.

[4] Leonelli C.; Boccaccini D. N; Veronesi P.; Barbieri L.; Lancellotti I; Andreola F.; Microwave thermal inertization of asbestos containing waste and recycling in traditional ceramics, Journal of Haz. Mat., in press.

[5] Sophia A.C., Swaminathan K. Assessment of the mechanical stability and chemical leachability of immobilized electroplating waste, Chemosfere 58, 2005, 75-82.

[6] Cheng N., Wei Y.L., Hsu L.H., Lee J.F., XAS study of chromium in thermally cured mixture of clay and Cr-containing plating sludge, J. Electron Spectroscopy and Related Phenomena 144-147, 2005, 821-823. 
30 Waste Management and the Environment III

[7] Manufacture of chromium-containing aventurine glass. (Mukai, Kenichi, Japan). Jpn. Kokai Tokyo Koho, 1985, Patent written in Japanese. Application: JP 83-121669 19830706.

[8] Engineered Materials Handbook, Ceramics and Glasses prepared under the direction of the ASM International Handbook Committee, Volume 4, (1991), Chemical durability, pp.856. 